\title{
Obesity-related metabolic disturbances and quality of life in subjects diagnosed with schizophrenia treated with atypical neuroleptics
}

\author{
Dariusz Ciura ${ }^{1}$, Jerzy Chudek ${ }^{2}$, Magdalena Olszanecka-Glinianowicz ${ }^{1}$ \\ ${ }^{1}$ Health Promotion and Obesity Management Unit, Department of Pathophysiology, Medical University of Silesia \\ in Katowice, Poland \\ 2Pathophysiology Unit, Department of Pathophysiology, Medical University of Silesia in Katowice, Poland
}

\begin{abstract}
Introduction: Weight gain and related metabolic disturbances are frequent side effects observed during treatment with atypical neuroleptics, most commonly with olanzapine and quetiapine. Weight gain may also deteriorate the quality of life and cause treatment discontinuation. However, the use of these neuroleptics in orodispensible tablet (ODT) form was related to lower frequency of weight gain. Therefore, the aim of this study was to evaluate the incidence of weight gain and metabolic disturbances in patients with schizophrenia treated with classical tablet (SOT) and orodispensible (ODT) formulations of olanzapine and quetiapine, and analyze the relationship between the occurrence of these side effects and quality of life and patient attitude to the treatment depending on the therapy used.
\end{abstract}

Material and methods: A three-month questionnaire survey was performed by 400 psychiatrists from across Poland, during three consecutive outpatient visits. 4437 adult patients with schizophrenia treated with atypical neuroleptics for at least one month but not more than 12 months were enrolled.

Results: Weight gain was significantly more common among patients treated with olanzapine than those treated with quetiapine ( $54.7 \%$ vs. $20 \%, p<0.001$ and $34.7 \%$ vs. $28.6 \%, p<0.01$, on visits 1 and 3 , respectively), and was less frequently observed in patients treated with ODT formulations. The prevalence of hypertension and type 2 diabetes on the treatment did not change significantly. Treatment with olanzapine regardless of the form used was associated with a better quality of life and a more positive attitude of the patient towards the treatment.

Conclusions: The risk of weight gain is greater during treatment with olanzapine than quetiapine. However, olanzapine use is associated with better quality of life and a more positive attitude of the patient towards the treatment. The use of neuroleptics in the ODT form may reduce the risk of weight gain but does not significantly affect the quality of life or the attitude of the patient towards the treatment.

Key words: obesity, schizophrenia, metabolic disturbances, atypical neuroleptics.

\section{Introduction}

Schizophrenia is a chronic disorder that significantly worsens the personal, professional and social life of patients [1]. Pharmacotherapy alleviates the symptoms of schizophrenia (abnormal things, perceiving, experiencing and mood), but its side effects may deteriorate quality of life, leading to discontinuation of treatment and relapse of the disease in about $50 \%$ of patients. It was observed that only $43 \%$ of patients with schizophrenia collaborate well in the therapeutic process [2], and as many as $40 \%$ of patients discontinue the pharmacotherapy within a year after the first hospitalization [3]. Subsequent relapses are a cause of increasing dysfunction, reduced periods of remission and longer duration of psychotic disorders [4].

Use of atypical neuroleptics (amisulpride, aripiprazole, quetiapine, clozapine, olanzapine, risperidone, paliperidone, sertindole, ziprasidone) as first-line drugs in the treat-

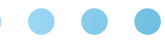

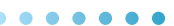


ment of schizophrenia increased not only their tolerance (reduced incidence of extrapyramidal disturbances) but also the effectiveness of elimination of deficits as well as affective and cognitive symptoms of schizophrenia. It should be emphasized that atypical antipsychotics are a heterogeneous class of drugs, and may differ both in terms of elimination of symptoms of schizophrenia and the side effect profile [5].

One of the most common side effects of classical and atypical neuroleptics is weight gain caused by an increase in the feeling of hunger and consequently increased food intake [6]. It seems that particularly the use of olanzapine and quetiapine increases the risk of weight gain, which is directly proportional to serum concentration of the drug [7]. Weight gain was observed in more than half of the patients treated with olanzapine $[8,9]$. The excess of body fat, especially visceral, is the cause of systemic inflammation, hormonal dysfunction of adipose tissue and insulin resistance development, which increases the risk of type 2 diabetes and cardiovascular diseases. Epidemiological studies have shown that the life expectancy of patients suffering from schizophrenia is $15-25$ years shorter than in the general population, which at least partially may be due to metabolic disorders induced by pharmacotherapy. It is suggested that the change from classical tablets (SOT) to an orodispensible (ODT) form reduces the risk of weight gain during treatment with olanzapine $[10,11]$. However, the results of recently published studies did not confirm this hypothesis [12]. On the other hand, Czekalla et al. [13] during treatment with ODT observed more adverse effects than during treatment with SOT (6.5\% vs. $2.9 \%)$. It is hypothesized that this is caused by absorption differences.

It should be stressed that side effects of an atypical neuroleptic, including weight gain, may affect the quality of life of patients, and thus their attitude to treatment and consequently the continued use of the prescribed medication.

Therefore, the aim of this study was to evaluate the incidence of weight gain and metabolic disturbances in patients with schizophrenia treated with SOT and ODT formulations of olanzapine and quetiapine, and analyze the relationship between the occurrence of these side effects and quality of life and patient attitude to the treatment depending on the therapy used.

\section{Material and methods}

The observational survey was performed by 400 psychiatrists from across Poland. The study group consisted of 4437 patients ( $48.8 \%$ women) treated for schizophrenia with atypical neuroleptics for at least one month but not more than 12 months prior to enrollment.

Recruitment to the study was performed in May and June 2010. The initial and two follow-up study visits were carried out at up to 3-month intervals, depending on the individual patient's clinical needs. All visits were part of routine management.

During the visits, a survey and measurements of anthropometric parameters (body mass and waist circumference) and blood pressure were performed. Serum glucose and lipid levels were noted in the survey if they were done before the start or during the 3-month follow-up. In addition, quality of life and daily functioning were assessed on the basis of selected questions from the Quality and Satisfaction of Life Questionnaire (Q-LES-Q-SF) and patients' attitude to the treatment on the basis of the Drug Attitude Inventory (DAI).

In addition to the above data, the conducted survey (visit I) included patient demographics [age, gender, place of residence: urban/rural, marital status: single/married/ widow/widower, domestic relations: living alone/with family, work activity: learning/working/unemployed/ pensioner], clinical data [age of schizophrenia diagnosis, duration of treatment, currently used neuroleptics, their doses and duration of use, and form (ODT/SOT) and the regularity of use]. Questions included body mass and blood pressure before initiation of atypical neuroleptic use. Medical history on the occurrence of hypertension and diabetes as well as antihypertensive and hypoglycemic therapy before treatment with neuroleptic and after its administration was taken.

The survey performed on control visits included questions concerning the continuation of treatment with a neuroleptic and potential reasons for its discontinuation, current dose and form (ODT/SOT) of neuroleptic and an assessment of its regular use, and antihypertensive and antidiabetic therapy.

\section{Data analysis}

The required data were entered automatically with the proper form (Microsoft Office Access). The percentage of missing data was less than $3.0 \%$ and those entries were not removed from the analysis as they were missing at random.

Nutritional status was assessed on the basis of BMI according to WHO criteria [14]. Visceral obesity was diagnosed by measuring waist circumference according to the International Diabetes Federation (IDF) criteria for Caucasians in Europe ( $\geq 80 \mathrm{~cm}$ for women and $\geq 94 \mathrm{~cm}$ for men) [15].

The prevalence of diabetes and hypertension was estimated on the basis of medical history as well as laboratory data and blood pressure measurements, respectively.

Weight gain of $3 \mathrm{~kg}$ or more was considered as significant.

\section{Statistical analysis}

An analysis of the age structure, gender, place of residence, marital status, family relations and labor force 
Table 1. Characteristics of the study group $(n=4437)$

\begin{tabular}{|c|c|}
\hline Age [years] & $39.6 \pm 1.4$ \\
\hline \multicolumn{2}{|l|}{ Age groups [\%] } \\
\hline $18-40$ years & 55.4 \\
\hline $41-50$ years & 22.2 \\
\hline $51-60$ years & 15.1 \\
\hline$>60$ years & 7.3 \\
\hline Gender: male/female [\%] & $51.2 / 48.8$ \\
\hline \multicolumn{2}{|l|}{ Place of residence [\%] } \\
\hline Village & 31.0 \\
\hline City & 69.0 \\
\hline \multicolumn{2}{|l|}{ Marital status [\%] } \\
\hline Single & 61.5 \\
\hline Married & 33.3 \\
\hline Widow/widower & 5.2 \\
\hline \multicolumn{2}{|l|}{ Home relations [\%] } \\
\hline Living alone & 20.8 \\
\hline Living with family & 79.2 \\
\hline \multicolumn{2}{|l|}{ Professional activity [\%] } \\
\hline Student & 12.0 \\
\hline Employed & 20.2 \\
\hline Unemployed & 9.5 \\
\hline Pensioner & 58.3 \\
\hline Age at diagnosis of schizophrenia [years] & $26.9 \pm 8.1$ \\
\hline \multicolumn{2}{|c|}{ Percentage of patients diagnosed with schizophrenia at age [\%] } \\
\hline$\leq 30$ years & 75.2 \\
\hline $31-40$ years & 19.3 \\
\hline $41-50$ years & 3.9 \\
\hline $51-60$ years & 1.3 \\
\hline$>60$ years & 0.3 \\
\hline \multicolumn{2}{|l|}{ BMI before treatment with neuroleptic $\left[\mathrm{kg} / \mathrm{m}^{2}\right]$} \\
\hline$<25[\%]$ & 45.5 \\
\hline $25-29.9[\%]$ & 44.8 \\
\hline$\geq 30[\%]$ & 9.7 \\
\hline \multicolumn{2}{|l|}{ BMI at time of enrollment $\left[\mathrm{kg} / \mathrm{m}^{2}\right]$} \\
\hline$<25[\%]$ & 38.5 \\
\hline $25-29.9[\%]$ & 47.2 \\
\hline$\geq 30[\%]$ & 14.3 \\
\hline \multicolumn{2}{|c|}{ Waist circumference before treatment with neuroleptic [\%] } \\
\hline Women $<80 \mathrm{~cm}$ & 51.0 \\
\hline Women $\geq 80 \mathrm{~cm}$ & 49.0 \\
\hline Men $<94 \mathrm{~cm}$ & 63.6 \\
\hline Men $\geq 94 \mathrm{~cm}$ & 36.4 \\
\hline
\end{tabular}

Waist circumference at time of enrollment [\%]

\begin{tabular}{|l|l|}
\hline Women $<80 \mathrm{~cm}$ & 48.1 \\
\hline Women $\geq 80 \mathrm{~cm}$ & 51.9 \\
\hline Men $<94 \mathrm{~cm}$ & 56.9 \\
\hline Men $\geq 94 \mathrm{~cm}$ & 43.1 \\
\hline
\end{tabular}

Blood pressure before treatment with neuroleptic [\%]

\begin{tabular}{l|r}
$<140 / 90$ & 75.5 \\
$\geq 140 / 90$ & 24.5
\end{tabular}

Blood pressure at time of enrollment [\%]

\begin{tabular}{|c|c|}
\hline$<140 / 90$ & 75.1 \\
\hline$\geq 140 / 90$ & 24.9 \\
\hline $\begin{array}{l}\text { Hypertension before treatment with } \\
\text { neuroleptic [\%] }\end{array}$ & 10.4 \\
\hline Treatment with hypotensive drug [\%] & 10.9 \\
\hline \multicolumn{2}{|c|}{ Diabetes before treatment with neuroleptic [\%] } \\
\hline Yes, only on diet & 1.9 \\
\hline Yes, pharmacotherapy & 1.6 \\
\hline
\end{tabular}

Diabetes at time of enrollment [\%]

\begin{tabular}{|c|c|}
\hline Yes, only on diet & 1.5 \\
\hline Yes, pharmacotherapy & 2.6 \\
\hline Laboratory tests performed before treatment [\%] & 37.7 \\
\hline Neuroleptic used [\%]
\end{tabular}

Neuroleptic used [\%]

\begin{tabular}{|l|c|}
\hline Risperidone & 0.4 \\
\hline Olanzapine & 97.0 \\
\hline Clozapine & 0.2 \\
\hline Quetiapine & 2.3 \\
\hline Ziprasidone & 0.1 \\
\hline Mean duration of use (months)
\end{tabular}

Mean duration of use (months)

\begin{tabular}{|l|c|}
\hline Risperidone & $6.3 \pm 3.2$ \\
\hline Olanzapine & $5.4 \pm 3.5$ \\
\hline Clozapine & $10.0 \pm 2.8$ \\
\hline Quetiapine & $6.0 \pm 2.6$ \\
\hline Ziprasidone & $4.0 \pm 1.4$ \\
\hline
\end{tabular}

\begin{tabular}{|l|c|}
\hline \multicolumn{2}{|l|}{ Mean daily dose $(\mathrm{mg})$} \\
\hline Risperidone & $5.3 \pm 2.3$ \\
\hline Olanzapine & $16 \pm 10$ \\
\hline Clozapine & $450 \pm 225$ \\
\hline Quetiapine & $525 \pm 150$ \\
\hline Ziprasidone & $120 \pm 0$ \\
\hline
\end{tabular}

Form of neuroleptic used [\%]

\begin{tabular}{|c|c|}
\hline SOT & 45.2 \\
\hline ODT & 54.8 \\
\hline \multicolumn{2}{|l|}{ Regularly taken [\%] } \\
\hline Yes & 95.8 \\
\hline
\end{tabular}


Table 2. Association between changes of body mass, metabolic disturbances and used neuroleptic

\begin{tabular}{|c|c|c|c|c|c|c|}
\hline & \multicolumn{2}{|c|}{ Visit I } & \multicolumn{2}{|c|}{ Visit II } & \multicolumn{2}{|c|}{ Visit III } \\
\hline & $\begin{array}{l}\text { Olanzapine } \\
(n=4304)\end{array}$ & $\begin{array}{l}\text { Quetiapine } \\
(n=102)\end{array}$ & $\begin{array}{l}\text { Olanzapine } \\
(n=4282)\end{array}$ & $\begin{array}{l}\text { Quetiapine } \\
\qquad(n=97)\end{array}$ & $\begin{array}{l}\text { Olanzapine } \\
(n=4258)\end{array}$ & $\begin{array}{c}\text { Quetiapine } \\
\quad(n=93)\end{array}$ \\
\hline \multicolumn{7}{|l|}{ Changes of body mass [\%] } \\
\hline Decreased & 9.5 & 20.0 & 20.0 & 14.3 & 20.6 & 9.5 \\
\hline Unchanged & 35.8 & 60.0 & 46.8 & 52.4 & 44.7 & 61.9 \\
\hline Increased & 54.7 & $20.0^{* \star *}$ & $33.2^{\# \# \#}$ & $33.3^{\# \#}$ & 34.7 & $28.6^{++}$ \\
\hline \multicolumn{7}{|c|}{ Hypertensive medications [\%] } \\
\hline Yes & 10.9 & 9.5 & 11.3 & 9.5 & 11.5 & $14.3^{++}$ \\
\hline \multicolumn{7}{|l|}{ Diabetes treatment [\%] } \\
\hline Yes, diet & 1.6 & 0 & 2.1 & 0 & 2.3 & 0 \\
\hline Yes, pharmacotherapy & 2.5 & 5.0 & 2.4 & 4.8 & 3.0 & 4.8 \\
\hline
\end{tabular}

${ }^{* * *} p<0.001$ olanzapine vs. quetiapine, ${ }^{\# \#} p<0.01,{ }^{\# \#} p<0.001$ visit II vs. visit I, ${ }^{++} p<0.01$ visit III vs. visit II

participation of the respondents was performed. We also analyzed the profile of used neuroleptics, their dose, form (ODT/SOT), the time of their application and regularity of use. In addition, the incidence of change in body mass and the occurrence of hypertension and diabetes were evaluated in relation to neuroleptics used and their formulation. Moreover, the association between quality of life or patients' attitude to the treatment and neuroleptics used and their formulations was evaluated.

Statistical analysis was performed using STATISTICA software 10.0 (Cracow, Poland).

Qualitative data were presented as percentages, and quantitative data as mean and standard deviation. The separate subgroups were compared using the $\chi^{2}$ test and $\chi^{2}$ test for trend. The value $p<0.05$ was considered as statistically significant.

\section{Results}

\section{Study group characteristics}

The characteristics of the study group are shown in Table 1 . In $75.2 \%$ of respondents schizophrenia was diagnosed before the age of 30 years. $55.4 \%$ of respondents were persons aged 40 years or less. As many as 58.3\% of respondents were pensioners. Only $33.3 \%$ of the study group had a partner. As many as $79.2 \%$ of the study population were living with their family.

The study design included patients treated with all atypical neuroleptics commercially available in Poland. $97.0 \%$ of the observed group were treated with olanzapine, $2.3 \%$ with quetiapine and only $0.7 \%$ with other atypical neuroleptics (risperidone, clozapine and ziprasidone). Both olanzapine and quetiapine were usually used in maximal doses of $20 \mathrm{mg}$ and $600 \mathrm{mg}$ respectively. The number of subjects limited the reasonable analysis to only two groups: patients treated with olanzapine and those treated with quetiapine. $45.2 \%$ of respondents used a SOT. $95.8 \%$ of patients reported regular use of neuroleptics.

Before starting treatment with a neuroleptic, overweight was diagnosed in $44.8 \%$ and obesity in $9.7 \%$ of study subjects, while visceral obesity was diagnosed in $49.0 \%$ of women and $36.4 \%$ of men. A significant increase in the prevalence of overweight and obesity was initially observed after the introduction of treatment with a neuroleptic $(47.2 \%$ vs. $44.8 \%, p<0.05$, and $14.3 \%$ vs. $9.7 \%$, $p<0.001)$. There was a parallel increase in the occurrence of visceral obesity among women $(51.9 \%$ vs. $49 \%, p<0.05)$ and among men $(63.6 \%$ vs. $36.4 \%, p<0.001)$.

Before starting treatment with a neuroleptic normal blood pressure $(<140 / 90)$ was observed in $75.5 \%$ of patients and after the start of treatment in $75.1 \%$.

Diabetes before neuroleptic treatment was diagnosed in $3.5 \%$ of the study group, and during the follow-up its incidence insignificantly increased to $4.1 \%$.

Plasma glucose and lipids before treatment with a neuroleptic were controlled in only $37.7 \%$ of the study group.

\section{Changes in body mass and metabolic disturbances depending on the used neuroleptic}

During the first visit of the survey, weight gain was observed significantly more frequently in patients treated with olanzapine than with quetiapine ( $54.7 \%$ vs. $20.0 \%, p<0.001$ ). However, on the second visit the percentage weight gain significantly decreased among subjects treated with olanzapine $(54.7 \%$ vs. $33.2 \%, p<0.001)$, but significantly increased among those treated with quetiapine $(20.0 \%$ vs. 33.3 , $p<0.01)$. On the third visit, the frequency of body mass gain stabilized among those treated with olanzapine (33.2\% vs. $34.7 \%$ ), and decreased among those treated with quetiapine $(33.3 \%$ vs. $28.6 \%, p<0.01)$ (Table 2$)$. 
Table 3. Association between changes of body mass, metabolic disturbances and the used form of neuroleptic

\begin{tabular}{|c|c|c|c|c|c|c|}
\hline & \multicolumn{2}{|c|}{ Visit I } & \multicolumn{2}{|c|}{ Visit II } & \multicolumn{2}{|c|}{ Visit III } \\
\hline & $\begin{array}{c}\text { SOT } \\
(n=4304)\end{array}$ & $\begin{array}{c}\text { ODT } \\
(n=102)\end{array}$ & $\begin{array}{c}\text { SOT } \\
(n=4282)\end{array}$ & $\begin{array}{c}\text { ODT } \\
(n=97)\end{array}$ & $\begin{array}{c}\text { SOT } \\
(n=4258)\end{array}$ & $\begin{array}{c}\text { ODT } \\
(n=93)\end{array}$ \\
\hline \multicolumn{7}{|l|}{ Changes of body mass [\%] } \\
\hline Decreased & 7.0 & 11.9 & 10.3 & 25.4 & 18.0 & 22.8 \\
\hline Unchanged & 31.8 & 40.1 & 52.7 & 44.5 & 46.7 & 44.5 \\
\hline Increased & 61.2 & $48.0^{\star \star}$ & 37.0 & $30.1^{\star \star}$ & 35.3 & $32.7^{*}$ \\
\hline \multicolumn{7}{|l|}{ Hypertensive medications [\%] } \\
\hline Yes & 12.3 & 9.7 & 10.8 & 11.6 & 10.8 & 12.0 \\
\hline \multicolumn{7}{|l|}{ Diabetes treatment [\%] } \\
\hline Yes, on diet & 1.7 & 1.4 & 0.3 & 3.0 & 0.3 & 3.0 \\
\hline Yes, on pharmacotherapy & 1.7 & 3.2 & 1.2 & 3.2 & 1.3 & 3.2 \\
\hline
\end{tabular}

${ }^{*} p<0.05,{ }^{* *} p<0.01$ SOT vs. ODT, ${ }^{\# \#} p<0.01,{ }^{\# \#} p<0.001$ visit II vs. visit I, ${ }^{++} p<0.01$ visit III vs. visit II

Table 4. The quality of life in relations to the used neuroleptic

\begin{tabular}{|c|c|c|c|c|c|c|}
\hline & \multicolumn{2}{|c|}{ Visit I } & \multicolumn{2}{|c|}{ Visit II } & \multicolumn{2}{|c|}{ Visit III } \\
\hline & $\begin{array}{l}\text { Olanzapine } \\
(n=4304)\end{array}$ & $\begin{array}{l}\text { Quetiapine } \\
(n=102)\end{array}$ & $\begin{array}{l}\text { Olanzapine } \\
(n=4282)\end{array}$ & $\begin{array}{l}\text { Quetiapine } \\
\qquad(n=97)\end{array}$ & $\begin{array}{l}\text { Olanzapine } \\
(n=4258)\end{array}$ & $\begin{array}{l}\text { Quetiapine } \\
\qquad(n=93)\end{array}$ \\
\hline \multicolumn{7}{|l|}{ Physical health [\%] } \\
\hline Very dissatisfied & 2.2 & 0 & 1.7 & 0 & 1.7 & 0 \\
\hline Dissatisfied & 17.0 & 19.1 & 10.2 & 14.3 & 8.0 & 0 \\
\hline Nor dissatisfied/nor satisfied & 37.9 & 57.1 & 36.9 & 57.1 & 26.7 & 71.4 \\
\hline Satisfied & 40.8 & 23.8 & $48.1^{\# \#}$ & $28.6^{\# \#}$ & $58.9^{++}$ & $28.6^{\star \star *}$ \\
\hline Very satisfied & 2.1 & 0 & 3.1 & 0 & 4.7 & 0 \\
\hline \multicolumn{7}{|l|}{ Mood [\%] } \\
\hline Very dissatisfied & 1.5 & 0 & 0.7 & 0 & 1.1 & 0 \\
\hline Dissatisfied & 20.6 & 14.3 & 9.8 & 0 & 6.8 & 0 \\
\hline Nor dissatisfied/nor satisfied & 39.4 & 47.6 & 38.1 & 57.1 & 25.4 & 42.9 \\
\hline Satisfied & 37.0 & 38.1 & $48.7^{\# \#}$ & $42.9^{\#}$ & $62.8^{+++}$ & $57.1^{+++\star \star}$ \\
\hline Very satisfied & 1.5 & 0 & 2.7 & 0 & 3.9 & 0 \\
\hline \multicolumn{7}{|l|}{ Work [\%] } \\
\hline Very dissatisfied & 1.2 & 0 & 2.7 & 0 & 2.4 & 0 \\
\hline Dissatisfied & 20.4 & 6.2 & 6.6 & 6.2 & 7.0 & 0 \\
\hline Nor dissatisfied/nor satisfied & 41.2 & 56.3 & 43.4 & 62.5 & 39.1 & 60.0 \\
\hline Satisfied & 36.3 & 37.5 & $43.4^{\# \#}$ & $31.3^{\# \#}$ & 44.5 & $40.0^{++* *}$ \\
\hline Very satisfied & 0.9 & 0 & 3.9 & 0 & 7.0 & 0 \\
\hline \multicolumn{7}{|l|}{ Household activities [\%] } \\
\hline Very dissatisfied & 1.7 & 0 & 0.6 & 0 & 0.9 & 0 \\
\hline Dissatisfied & 18.3 & 14.3 & 10.4 & 0 & 40.8 & 47.6 \\
\hline Nor dissatisfied/nor satisfied & 45.5 & 61.9 & 47.7 & 57.1 & 0 & 0 \\
\hline Satisfied & 33.5 & 23.8 & $45.5^{\# \#}$ & $42.9^{\# \#}$ & $52.4^{++}$ & $52.4^{+++*}$ \\
\hline Very satisfied & 1.0 & 0 & 2.8 & 0 & 5.9 & 0 \\
\hline
\end{tabular}


Table 4. Cont.

\begin{tabular}{|c|c|c|c|c|c|c|}
\hline & \multicolumn{2}{|c|}{ Visit I } & \multicolumn{2}{|c|}{ Visit II } & \multicolumn{2}{|c|}{ Visit III } \\
\hline & $\begin{array}{l}\text { Olanzapine } \\
(n=4304)\end{array}$ & $\begin{array}{l}\text { Quetiapine } \\
(n=102)\end{array}$ & $\begin{array}{l}\text { Olanzapine } \\
(n=4282)\end{array}$ & $\begin{array}{l}\text { Quetiapine } \\
(n=97)\end{array}$ & $\begin{array}{l}\text { Olanzapine } \\
(n=4258)\end{array}$ & $\begin{array}{c}\text { Quetiapine } \\
(n=93)\end{array}$ \\
\hline \multicolumn{7}{|l|}{ Contact with friends [\%] } \\
\hline Very dissatisfied & 2.6 & 0 & 0.8 & 0 & 1.1 & 0 \\
\hline Dissatisfied & 27.2 & 14.3 & 14.6 & 9.5 & 9.1 & 0 \\
\hline Nor dissatisfied/nor satisfied & 44.1 & 47.6 & 47.2 & 52.4 & 42.3 & 57.1 \\
\hline Satisfied & 24.7 & 28.6 & $34.4^{\# \#}$ & $33.3^{\#}$ & $43.3^{++}$ & $42.9^{+++^{*}}$ \\
\hline Very satisfied & 1.4 & 9.5 & 3.0 & 4.8 & 4.2 & 0 \\
\hline \multicolumn{7}{|l|}{ Contact with family [\%] } \\
\hline Very dissatisfied & 1.9 & 0 & 1.9 & 0 & 1.2 & 0 \\
\hline Dissatisfied & 23.8 & 14.3 & 12.7 & 4.8 & 9.8 & 0 \\
\hline Nor dissatisfied/nor satisfied & 37.7 & 61.9 & 31.8 & 81.0 & 28.9 & 57.1 \\
\hline Satisfied & 34.6 & 23.8 & $49.3^{\# \# \#}$ & $9.5^{\# \# \# ~}$ & $54.2^{+}$ & $38.1^{+++\star *}$ \\
\hline Very satisfied & 1.9 & 0 & 4.3 & 4.7 & 5.9 & 4.8 \\
\hline \multicolumn{7}{|l|}{ Free time activities [\%] } \\
\hline Very dissatisfied & 2.1 & 0 & 0.8 & 0 & 0.6 & 0 \\
\hline Dissatisfied & 22.6 & 14.3 & 11.0 & 0 & 7.9 & 0 \\
\hline Nor dissatisfied/nor satisfied & 48.2 & 71.4 & 43.6 & 76.2 & 36.7 & 47.6 \\
\hline Satisfied & 26.2 & 14.3 & $41.6^{\# \# \#}$ & $23.8^{\# \# \#}$ & $49.0^{++}$ & $47.6^{+++}$ \\
\hline Very satisfied & 0.9 & 0 & 3.0 & 0 & 5.8 & 4.8 \\
\hline \multicolumn{7}{|c|}{ Ability to functioning in everyday life [\%] } \\
\hline Very dissatisfied & 2.5 & 0 & 1.8 & 0 & 1.4 & 0 \\
\hline Dissatisfied & 21.8 & 23.8 & 11.2 & 4.8 & 8.5 & 0 \\
\hline Nor dissatisfied/nor satisfied & 43.0 & 52.4 & 40.6 & 71.4 & 31.8 & 61.9 \\
\hline Satisfied & 32.0 & 23.8 & $43.1^{\# \# \#}$ & 23.8 & $52.4^{++}$ & $38.1^{+++^{\star \star \star}}$ \\
\hline Very satisfied & 0.7 & 0 & 3.3 & 0 & 5.9 & 0 \\
\hline \multicolumn{7}{|l|}{ Sexual life [\%] } \\
\hline Very dissatisfied & 8.5 & 0 & 6.6 & 0 & 4.5 & 0 \\
\hline Dissatisfied & 37.3 & 57.1 & 29.5 & 47.6 & 25.5 & 42.8 \\
\hline Nor dissatisfied/nor satisfied & 42.2 & 23.8 & 42.8 & 42.9 & 41.6 & 42.9 \\
\hline Satisfied & 11.6 & 19.1 & $19.0^{\# \#}$ & $9.5^{\# \#}$ & $26.3^{++}$ & $14.3^{++^{\star \star \star}}$ \\
\hline Very satisfied & 0.4 & 0 & 2.1 & 0 & 2.1 & 0 \\
\hline \multicolumn{7}{|l|}{ Physical and mental health [\%] } \\
\hline Very dissatisfied & 2.6 & 0 & 2.3 & 0 & 2.3 & 0 \\
\hline Dissatisfied & 19.7 & 23.8 & 9.7 & 14.3 & 7.8 & 28.6 \\
\hline Nor dissatisfied/nor satisfied & 46.2 & 52.4 & 42.2 & 66.7 & 32.7 & 47.6 \\
\hline Satisfied & 30.3 & 23.8 & $42.7^{\# \#}$ & 19.0 & $51.9^{++}$ & $23.8^{+\star \star \star}$ \\
\hline Very satisfied & 1.2 & 0 & 3.1 & 0 & 5.3 & 0 \\
\hline
\end{tabular}

${ }^{*} p<0.05,{ }^{* *} p<0.01, p<0.001$ olanzapine vs. quetiapine, ${ }^{\#} p<0.05,{ }^{\# \#} p<0.01,{ }^{\# \# \#} p<0.001$ visit II vs. visit $I,{ }^{+} p<0.05,{ }^{++} p<0.01,{ }^{+++} p<0.001$ visit III vs. visit II 
Table 5. Quality of life in relation to the form of used neuroleptic

\begin{tabular}{|c|c|c|c|c|c|c|}
\hline & \multicolumn{2}{|c|}{ Visit I } & \multicolumn{2}{|c|}{ Visit II } & \multicolumn{2}{|c|}{ Visit III } \\
\hline & $\begin{array}{c}\text { SOT } \\
(n=4304)\end{array}$ & $\begin{array}{c}\text { ODT } \\
(n=102)\end{array}$ & $\begin{array}{c}\text { SOT } \\
(n=4282)\end{array}$ & $\begin{array}{c}\text { ODT } \\
(n=97)\end{array}$ & $\begin{array}{c}\text { SOT } \\
(n=4258)\end{array}$ & $\begin{array}{c}\text { ODT } \\
(n=93)\end{array}$ \\
\hline \multicolumn{7}{|l|}{ Physical health [\%] } \\
\hline Very dissatisfied & 1.7 & 2.4 & 2.1 & 1.4 & 1.3 & 1.8 \\
\hline Dissatisfied & 16.4 & 17.4 & 9.0 & 10.9 & 7.8 & 7.8 \\
\hline Nor dissatisfied/nor satisfied & 34.1 & 41.7 & 34.6 & 39.2 & 27.5 & 28.1 \\
\hline Satisfied & 45.1 & 37.1 & $50.9^{\#}$ & $45.7^{\#}$ & $57.2^{+}$ & $58.6^{+}$ \\
\hline Very satisfied & 2.7 & 1.4 & 3.4 & 2.8 & 6.2 & 3.7 \\
\hline \multicolumn{7}{|l|}{ Mood [\%] } \\
\hline Very dissatisfied & 1.5 & 1.4 & 0.6 & 0.7 & 1.0 & 1.1 \\
\hline Dissatisfied & 19.1 & 21.3 & 11.1 & 8.6 & 8.2 & 5.8 \\
\hline Nor dissatisfied/nor satisfied & 35.0 & 43.1 & 33.9 & 40.9 & 24.8 & 26.3 \\
\hline Satisfied & 42.4 & 33.2 & $51.9^{\# \#}$ & $47.1^{\# \#}$ & $62.1^{++}$ & $63.1^{++}$ \\
\hline Very satisfied & 2.0 & 1.0 & 2.5 & 2.7 & 3.9 & 3.7 \\
\hline \multicolumn{7}{|l|}{ Work [\%] } \\
\hline Very dissatisfied & 1.1 & 1.2 & 2.8 & 2.4 & 3.6 & 1.4 \\
\hline Dissatisfied & 14.9 & 24.4 & 11.1 & 3.4 & 9.4 & 4.8 \\
\hline Nor dissatisfied/nor satisfied & 50.9 & 33.1 & 48.6 & 41.6 & 42.1 & 38.6 \\
\hline Satisfied & 32.0 & 40.7 & 35.4 & $47.8^{\#}$ & $42.0^{+}$ & $46.2^{\star \star}$ \\
\hline Very satisfied & 1.1 & 0.6 & 2.1 & 4.8 & 2.9 & 9.0 \\
\hline \multicolumn{7}{|l|}{ Household activities [\%] } \\
\hline Very dissatisfied & 2.0 & 1.4 & 0.6 & 0.5 & 0 & 0 \\
\hline Dissatisfied & 15.9 & 19.8 & 10.8 & 9.7 & 2.3 & 0.2 \\
\hline Nor dissatisfied/nor satisfied & 45.1 & 46.6 & 40.4 & 41.1 & 41.8 & 40.3 \\
\hline Satisfied & 35.5 & 31.6 & $45.7^{\# \#}$ & $45.9^{\# \# \#}$ & $52.0^{+}$ & $52.8^{+* \star}$ \\
\hline Very satisfied & 1.5 & 0.6 & 2.5 & 2.8 & 3.9 & 6.7 \\
\hline \multicolumn{7}{|l|}{ Contact with friends [\%] } \\
\hline Very dissatisfied & 3.2 & 2.0 & 0.9 & 0.7 & 2.6 & 0.2 \\
\hline Dissatisfied & 25.7 & 27.7 & 16.7 & 13.2 & 11.4 & 7.4 \\
\hline Nor dissatisfied/nor satisfied & 43.9 & 44.6 & 45.5 & 48.1 & 41.5 & 43.5 \\
\hline Satisfied & 26.0 & 23.9 & $35.6^{\# \#}$ & $33.9^{\# \#}$ & $42.5^{+}$ & $43.6^{++*}$ \\
\hline Very satisfied & 1.2 & 1.8 & 1.3 & 4.1 & 2.0 & 5.3 \\
\hline \multicolumn{7}{|l|}{ Contact with family [\%] } \\
\hline Very dissatisfied & 1.7 & 2.0 & 2.5 & 1.4 & 2.3 & 0.5 \\
\hline Dissatisfied & 22.5 & 24.3 & 13.6 & 11.8 & 10.8 & 8.9 \\
\hline Nor dissatisfied/nor satisfied & 34.1 & 41.7 & 32.1 & 33.9 & 28.8 & 30.3 \\
\hline Satisfied & 39.7 & 30.2 & $49.4^{\# \#}$ & $47.6^{\# \# \#}$ & 53.9 & $53.6^{+}$ \\
\hline Very satisfied & 2.0 & 1.8 & 2.4 & 5.3 & 4.2 & 6.7 \\
\hline \multicolumn{7}{|l|}{ Free time activities [\%] } \\
\hline Very dissatisfied & 2.4 & 1.6 & 0.9 & 0.7 & 1.6 & 0 \\
\hline Dissatisfied & 20.1 & 24.3 & 11.7 & 10.1 & 10.5 & 6.2 \\
\hline Nor dissatisfied/nor satisfied & 48.3 & 49.4 & 45.4 & 43.6 & 37.3 & 36.6 \\
\hline Satisfied & 28.7 & 23.5 & $41.1^{\# \#}$ & $41.6^{\# \# \#}$ & $47.7^{++}$ & $49.9^{++* * *}$ \\
\hline Very satisfied & 0.5 & 1.2 & 0.9 & 4.0 & 2.9 & 7.3 \\
\hline
\end{tabular}


Table 5. Cont.

\begin{tabular}{|c|c|c|c|c|c|c|}
\hline & \multicolumn{2}{|c|}{ Visit I } & \multicolumn{2}{|c|}{ Visit II } & \multicolumn{2}{|c|}{ Visit III } \\
\hline & $\begin{array}{c}\text { SOT } \\
(n=4304)\end{array}$ & $\begin{array}{c}\text { ODT } \\
(n=102)\end{array}$ & $\begin{array}{c}\text { SOT } \\
(n=4282)\end{array}$ & $\begin{array}{c}\text { ODT } \\
(n=97)\end{array}$ & $\begin{array}{c}\text { SOT } \\
(n=4258)\end{array}$ & $\begin{array}{c}\text { ODT } \\
(n=93)\end{array}$ \\
\hline \multicolumn{7}{|c|}{ Ability to function in everyday life [\%] } \\
\hline Very dissatisfied & 2.2 & 2.6 & 2.2 & 1.6 & 2.3 & 0.9 \\
\hline Dissatisfied & 20.1 & 23.3 & 13.0 & 9.9 & 9.8 & 7.4 \\
\hline Nor dissatisfied/nor satisfied & 40.2 & 45.5 & 41.5 & 40.9 & 34.3 & 32.3 \\
\hline Satisfied & 36.3 & 28.3 & $41.8^{\#}$ & $43.6^{\# \#}$ & $50.0^{++}$ & $53.5^{++\star \star \star}$ \\
\hline Very satisfied & 1.2 & 0.2 & 1.5 & 4.0 & 3.6 & 6.9 \\
\hline \multicolumn{7}{|l|}{ Sexual life [\%] } \\
\hline Very dissatisfied & 7.4 & 9.1 & 7.7 & 5.6 & 6.2 & 3.3 \\
\hline Dissatisfied & 33.8 & 40.7 & 29.0 & 30.5 & 26.5 & 25.8 \\
\hline Nor dissatisfied/nor satisfied & 46.3 & 38.3 & 45.7 & 41.5 & 45.8 & 39.6 \\
\hline Satisfied & 12.0 & 11.5 & $17.6^{\#}$ & $19.2^{\#}$ & $21.5^{+}$ & $28.1+^{* * *}$ \\
\hline Very satisfied & 0.5 & 0.4 & 0 & 3.2 & 0 & 3.2 \\
\hline \multicolumn{7}{|l|}{ Physical and mental health [\%] } \\
\hline Very dissatisfied & 2.4 & 2.6 & 3.1 & 1.8 & 3.3 & 1.6 \\
\hline Dissatisfied & 19.4 & 19.8 & 12.0 & 8.5 & 11.4 & 6.5 \\
\hline Nor dissatisfied/nor satisfied & 42.1 & 49.6 & 41.0 & 43.7 & 33.3 & 33.0 \\
\hline Satisfied & 35.6 & 26.9 & $41.4^{\#}$ & $42.7^{7 \# \#}$ & $48.1^{+}$ & $53.0^{+++\star *}$ \\
\hline Very satisfied & 1.5 & 1.1 & 2.5 & 3.3 & 3.9 & 5.9 \\
\hline
\end{tabular}

${ }^{*} p<0.05,{ }^{* *} p<0.01, p<0.001$ SOT vs. ODT, ${ }^{\#} p<0.05,{ }^{\# \#} p<0.01,{ }^{\# \#} p<0.001$ visit II vs. visit I, ${ }^{+} p<0.05,{ }^{++} p<0.01,{ }^{+++} p<0.001$ visit III vs. visit II

During all visits weight gain was significantly more frequently observed among subjects treated with SOT than with ODT $(61.2 \%$ vs. $48.0 \%, p<0.001 ; 37.0 \%$ vs. $30.1 \%$, $p<0.01$; and $35.2 \%$ vs. $32.7 \%, p<0.05$, respectively) (Table 3).

During the observation the percentage of subjects on antihypertensive therapy did not change significantly among patients treated with olanzapine ( $10.9 \%$ vs. $11.5 \%$ vs. $11.3 \%)$, regardless of the used form of neuroleptic. However, on the second visit the percentage of subjects on antihypertensive therapy increased significantly among subjects using quetiapine ( $14.3 \%$ vs. $9.5 \%, p<0.01)$ (Table 2$)$.

The prevalence of diabetes remained unchanged during the observation period (Table 2), and was unaffected by the used form of neuroleptic (Table 3 ).

\section{Association between quality of life and used neuroleptic and its form}

In both groups treated with olanzapine and quetiapine there was a significant improvement of satisfaction with physical health, mood, work, household activity, contacts with friends and with family, spending free time and ability to function in everyday life. However, an improvement of satisfaction with sexual life as well as physical and mental life was found only in the group treated with olanzapine (Table 4).
At the end of the study the percentage of subjects very satisfied and satisfied with physical health and mood was significant higher among patients treated with olanzapine than those treated with quetiapine (63.6\% vs. $28.6 \%$, $p<0.001$ and $66.7 \%$ vs. $57.1 \%, p<0.01$, respectively). Moreover, the percentage of subjects very satisfied and satisfied with work and household activity was significantly higher among patients treated with olanzapine than those treated with quetiapine $(51.5 \%$ vs. $46 \%, p<0.01$ and $58.3 \%$ vs. $52.4 \%, p<0.05$, respectively). Furthermore, the percentage of subjects very satisfied and satisfied with contacts with friends and with family was significantly higher among patients treated with olanzapine than those treated with quetiapine $(47.5 \%$ vs. $42.9 \%, p<0.05$ and $60.1 \%$ vs. $42.9 \%, p<0.01$, respectively). There were no differences in the percentage of subjects very satisfied and satisfied with spending free time between those treated with olanzapine and those treated with quetiapine (54.8\% vs. $52.4 \%)$. In addition, the percentage of subjects very satisfied and satisfied with ability to function in everyday life, sex life as well as physical and mental life was significant higher among patients treated with olanzapine than those treated with quetiapine (58.3\% vs. $38.1 \%$, $p<0.001 ; 28.4 \%$ vs. $14.3 \%, p<0.001$ and $57.2 \%$ vs. $23.8 \%$, $p<0.001$, respectively) (Table 4 ). 
Table 6. Attitude of the patient to the drug in relation to the used neuroleptic

\begin{tabular}{|c|c|c|c|c|c|c|}
\hline & \multicolumn{2}{|c|}{ Visit I } & \multicolumn{2}{|c|}{ Visit II } & \multicolumn{2}{|c|}{ Visit III } \\
\hline & $\begin{array}{l}\text { Olanzapine } \\
(n=4304)\end{array}$ & $\begin{array}{l}\text { Quetiapine } \\
(n=102)\end{array}$ & $\begin{array}{l}\text { Olanzapine } \\
(n=4282)\end{array}$ & $\begin{array}{l}\text { Quetiapine } \\
(n=97)\end{array}$ & $\begin{array}{l}\text { Olanzapine } \\
(n=4258)\end{array}$ & $\begin{array}{c}\text { Quetiapine } \\
(n=93)\end{array}$ \\
\hline \multicolumn{7}{|c|}{ Good effects of the drug outweigh the bad effects [\%] } \\
\hline True & 86.6 & $52.4^{* * *}$ & $90.7^{\#}$ & $61.9^{\# \# * * *}$ & $94.3^{+}$ & $66.7^{* * \star}$ \\
\hline \multicolumn{7}{|c|}{ I feel strange when I take the drug [\%] } \\
\hline True & 22.9 & $61.9^{* \star *}$ & $20.2^{\#}$ & $47.6^{\# \# \# * * *}$ & $18.2^{+}$ & $38.1^{++* * *}$ \\
\hline \multicolumn{7}{|c|}{ I take the medication voluntarily [\%] } \\
\hline True & 85.8 & $95.2^{* *}$ & $88.9^{\#}$ & $100.0^{\# * * *}$ & $91.5^{+}$ & $95.2^{+*}$ \\
\hline \multicolumn{7}{|c|}{ The drug makes me feel more relaxed [\%] } \\
\hline True & 65.1 & $52.4^{* *}$ & $74.5^{\# \#}$ & $52.4^{\star * *}$ & $80.6^{+}$ & $61.9^{+* * *}$ \\
\hline \multicolumn{7}{|c|}{ The drug causes fatigue and heaviness [\%] } \\
\hline True & 40.1 & $61.9^{\star \star \star}$ & $35.2^{\#}$ & $61.9^{\star \star \star}$ & $28.4^{+}$ & $47.6^{++* * *}$ \\
\hline \multicolumn{7}{|c|}{ I take the medication only when I'm sick [\%] } \\
\hline True & 36.8 & $57.1^{* *}$ & 34.1 & $47.6^{\# \# * *}$ & $31.8^{+}$ & $42.9^{+* *}$ \\
\hline \multicolumn{7}{|c|}{ I feel more normal when I use the drug [\%] } \\
\hline True & 74.3 & $52.4^{* * *}$ & $82.3^{\#}$ & $52.4^{\star * *}$ & 85.9 & $52.4^{* * \star}$ \\
\hline \multicolumn{7}{|c|}{ It is unnatural when the drug controls my mind and body [\%] } \\
\hline True & 43.9 & $71.4^{\star \star \star}$ & 39.1 & $57.1^{\# \# * \star *}$ & 36.6 & $61.9^{\star \star \star}$ \\
\hline \multicolumn{7}{|c|}{ Thanks to the drug I can think more clearly [\%] } \\
\hline True & 77.6 & $52.4^{* \star *}$ & $85.1^{\#}$ & $57.1^{\# * * *}$ & 89.2 & $61.9^{* \star \star}$ \\
\hline \multicolumn{7}{|c|}{ By taking the medication I can prevent the disease [\%] } \\
\hline True & 85.0 & $52.4^{\star \star \star}$ & $90.9^{\#}$ & $90.5^{\# \# \#}$ & 94.3 & $100.0^{++*}$ \\
\hline
\end{tabular}

${ }^{*} p<0.05,{ }^{* *} p<0.01, p<0.001$ olanzapine vs. quetiapine, ${ }^{\#} p<0.05,{ }^{\# \#} p<0.01,{ }^{\# \#} p<0.001$ visit II vs. visit $1,{ }^{+} p<0.05,{ }^{++} p<0.01,{ }^{+++} p<0.001$ visit III vs. visit II

In both groups treated with SOT and ODT a significant improvement of satisfaction with physical health, mood, work, household activity, contacts with friends and with family, spending free time and ability to function in everyday life, sexual life as well as physical and mental life occurred (Table 5).

The percentage of subjects very satisfied and satisfied with physical health and mood at the end of the study did not differ between those treated with SOT and those treated with ODT ( $63.4 \%$ vs. $62.3 \%$ and $66.0 \%$ vs. $66.8 \%$, respectively). The percentage of subjects very satisfied and satisfied with work and household activity was significantly higher among those treated with ODT than those treated with SOT $(55.2 \%$ vs. $44.9, p<0.01$ and $62.5 \%$ vs. $55.9 \%, p<0.01$, respectively). Furthermore, the percentage of subjects very satisfied and satisfied with contacts with friends was significantly higher among those treated with ODT than those treated with SOT ( $48.9 \%$ vs. $44.5 \%$, $p<0.05)$. However, the percentage of subjects very satisfied and satisfied with contacts with family did not differ between those treated with ODT than those treated with SOT (60.3\% vs. $58.1 \%)$. Finally, the percentage of subjects very satisfied and satisfied with spending free time, ability to function in everyday life, sex life as well as physical and mental life was significant higher among those treated with ODT than those treated with SOT (57.2\% vs. $50.6 \%$, $p<0.001 ; 60.4 \%$ vs. $53.6 \%, p<0.001$ and $31.3 \%$ vs. $21.5 \%$, $p<0.001$ and $58.9 \%$ vs. $52.0 \%, p<0.01$, respectively) (Table 5).

\section{Attitude of study subjects to the treatment and used neuroleptic and its form}

During successive visits, the percentage of subjects who supposed that the good effects of the drug outweighed the bad effects significantly increased in both groups, and was significantly higher among those treated with olanzapine than those treated with quetiapine (Table 6).

Also the percentage of subjects who state that they feel strange when taking the drugs during successive evaluations decreased in both groups, but was significantly lower among those treated with olanzapine than those treated with quetiapine (Table 6).

During successive visits, the percentage of subjects reporting voluntary use of drugs was lower among those treated with olanzapine than those treated with quetiapine. The increase in the percentage of subjects 
Table 7. Attitude of the patient to the drug in relation to the used form of neuroleptic

\begin{tabular}{|c|c|c|c|c|c|c|}
\hline & \multicolumn{2}{|c|}{ Visit I } & \multicolumn{2}{|c|}{ Visit II } & \multicolumn{2}{|c|}{ Visit III } \\
\hline & $\begin{array}{c}\text { SOT } \\
(n=4304)\end{array}$ & $\begin{array}{c}\text { ODT } \\
(n=102)\end{array}$ & $\begin{array}{c}\text { SOT } \\
(n=4282)\end{array}$ & $\begin{array}{c}\text { ODT } \\
(n=97)\end{array}$ & $\begin{array}{c}\text { SOT } \\
(n=4258)\end{array}$ & $\begin{array}{c}\text { ODT } \\
(n=93)\end{array}$ \\
\hline \multicolumn{7}{|c|}{ Good effects of the drug outweigh the bad effects [\%] } \\
\hline True & 84.8 & 86.8 & $88.0^{\#}$ & $91.4^{\#}$ & $92.2^{+}$ & $94.4^{+}$ \\
\hline \multicolumn{7}{|c|}{ I feel strange when I take the drug [\%] } \\
\hline True & 23.8 & 24.1 & $18.8^{\#}$ & 22.1 & 18.0 & $19.6^{+}$ \\
\hline \multicolumn{7}{|c|}{ I take the medication voluntarily [\%] } \\
\hline True & 90.2 & $82.8^{*}$ & 92.9 & $87.1^{\# *}$ & $94.1^{+}$ & $89.8^{+*}$ \\
\hline \multicolumn{7}{|c|}{ The drug makes me feel more relaxed [\%] } \\
\hline True & 66.4 & $63.4^{*}$ & $73.5^{\# \#}$ & $74.2^{\# \#}$ & 76.8 & $81.3^{++*}$ \\
\hline \multicolumn{7}{|c|}{ The drug causes fatigue and heaviness [\%] } \\
\hline True & 42.4 & 39.3 & $36.1^{\#}$ & $35.7^{\#}$ & $30.4^{+}$ & $28.2^{+}$ \\
\hline \multicolumn{7}{|c|}{ I take the medication only when I'm sick [\%] } \\
\hline True & 33.1 & 40.5 & 28.7 & 37.5 & 24.2 & 35.6 \\
\hline \multicolumn{7}{|c|}{ I feel more normal when I use the drugs [\%] } \\
\hline True & 76.7 & 71.1 & 83.0" & $80.8^{\#}$ & 85.0 & $84.4^{+}$ \\
\hline \multicolumn{7}{|c|}{ It is unnatural when the drug controls my mind and body [\%] } \\
\hline True & 45.1 & 44.4 & $34.6^{\# \#}$ & $42.3^{*}$ & 34.8 & $38.1^{+*}$ \\
\hline \multicolumn{7}{|c|}{ Thanks to the drug I can think more clearly [\%] } \\
\hline True & 79.2 & 75.3 & $85.2^{\#}$ & $84.1^{\#}$ & 88.2 & $88.7^{+}$ \\
\hline \multicolumn{7}{|c|}{ By taking the medication I can prevent the disease [\%] } \\
\hline True & 88.7 & 82.6 & $92.9^{\#}$ & $89.8^{\#}$ & 94.4 & $94.2^{+}$ \\
\hline
\end{tabular}

${ }^{*} p<0.05$ SOT vs. ODT, ${ }^{\#} p<0.05 ;{ }^{\# \#} p<0.01, \# \# p 0.001$ visit II vs. visit I, ${ }^{+} p<0.05,{ }^{++} p<0.01,{ }^{+++} p<0.001$ visit III vs. visit II

who voluntarily used drugs during the follow-up increased among those treated with olanzapine only (Table 6).

The feeling of relaxation during the use of drug was more frequently reported by subjects treated with olanzapine than those treated with quetiapine on all visits. In addition, during the follow-up the percentage of subjects feeling relaxation increased significantly in the group treated with olanzapine only (Table 6).

On all visits the feeling of fatigue and heaviness during the use of the drug was less frequently reported by those treated with olanzapine than those treated with quetiapine. The percentage of subjects expressing this opinion decreased significantly at the end of the study in both groups (Table 6).

At the beginning of the study, subjects treated with olanzapine less frequently than those treated with quetiapine reported that they used the drug when they fell ill. The proportion of people expressing this opinion significantly decreased during the observation in both groups (Table 6).

Feeling more normal during the use of drugs was more frequently expressed by subjects treated with olan- zapine than those treated with quetiapine, and increased with time of treatment with olanzapine, only (Table 6).

Patients treated with olanzapine significantly less frequently than those taking quetiapine believed that the control of their mind and body by drugs is unnatural. Moreover, during follow-up a decrease in the percentage of subjects expressing this opinion was found among subjects treated with olanzapine, only (Table 6).

Furthermore, patients treated with olanzapine significantly more often than those taking quetiapine stated that thanks to the drug they can think more clearly. The percentage of subjects expressing this opinion significantly increased with time of follow-up in both groups (Table 6).

At the end of the study the proportion of patients who reported that they take drugs to prevent the disease relapse was greater than at the beginning, and among treated with olanzapine than those treated with quetiapine (Table 6).

During the successive visits the percentage of subjects who believe that the good effects of the drug outweigh the bad effects and were feeling relaxed was lower among those treated with SOT than among those treated with 
ODT. The percentages increased significantly during the follow-up in both groups (Table 7).

The percentage of subjects who report that they feel strange when taking medication was comparable in those treated with SOT and those treated with ODT, and decreased with time of observation in both groups (Table 7).

There were more subjects reporting voluntary drug use among those treated with SOT than those treated with ODT. During follow-up an increase in the percentage of subjects using the drug voluntarily was found among those treated with ODT, only (Table 7).

Patients treated with SOT less frequently than those treated with ODT reporting taking the drug when feeling ill. During follow-up the percentage of subjects expressing this opinion decreased significantly in both groups (Table 7).

At the end of the study there were no differences in the percentage of subjects who feel more normal during drug use between those treated with SOT and those treated with ODT. In addition, during the follow-up the percentage of subjects expressing this opinion increased significantly in both groups. The percentage of subjects stating that control of their mind and body by drugs is unnatural was significantly lower among those treated with SOT than those treated with ODT. During the follow-up the percentage of subjects expressing this opinion decreased significantly among those treated with ODT, only (Table 7).

Finally, there was no difference between the groups in the percentage of subjects stating that thanks to the drug they can think more clearly and that by using the drugs they can prevent the disease (Table 7).

\section{Discussion}

The prevalence of obesity in the study group before inclusion of the neuroleptic was lower than in the general adult Polish population (9.7\% vs. 20.4\%) [14]. While, the percentage of subjects diagnosed with visceral obesity among both women and men was higher than among the general Polish population (49.0\% vs. $40.4 \%$ and $36.4 \%$ vs. $28.3 \%$, respectively) [16]. However, it should be noted that the main cause of these differences is the use of more restrictive diagnostic criteria than in the WOBASZ study (IDF 2005 vs. NCEP-ATP III in 2001) and does not warrant the finding that visceral obesity in people with schizophrenia is more common than in the general population [16].

The results of our study confirm previously published observations that treatment with olanzapine and quetiapine is associated with development of overweight and obesity [7], and visceral fat distribution, especially among men. However, this did not result in a significant increase the prevalence of hypertension and type 2 diabetes in the study population. It should be emphasized that while the blood pressure measurements were performed on all the visits, the serum glucose concentrations was determined in less than $38 \%$ of respondents. Therefore, there is a high probability of underestimating the newly occurring type 2 diabetes, and the present results do not allow one to draw any conclusion concerning the risk of type 2 diabetes development in patients with weight gain on treatment with atypical neuroleptics. In addition, the short 3-month period of observation in many cases was too short for the development of this late complication of obesity.

In accordance with the results of previous studies, after initiation of treatment with olanzapine weight gain was observed in over $50 \%$ of patients $[8,9]$. This percentage was higher than among those treated with quetiapine; however, during the 3-month follow-up weight gain also occurred in over $1 / 3$ of those treated with this drug. Thus, the results of the present study confirm previous observations showing that treatment with olanzapine and quetiapine is associated with a high risk for weight gain [7]. It should also be noted that the tendency to weight gain during treatment with olanzapine decreased with the duration of therapy.

Neuroleptic in ODT form at baseline was used in 54.8\% of the study population. According to the results of some previous studies $[10,11]$, but in contrast to a recently published study [12], the use of neuroleptics in the ODT form was associated with a lower risk of weight gain than SOT. However, there was no association between the form used and the incidence of hypertension and type 2 diabetes. The strength of this finding is limited by the low rate of blood sampling (38.0\%), precluding drawing a strong conclusion about the impact of the neuroleptics on the incidence of type 2 diabetes. Therefore, the effect of different forms of neuroleptics on the risk of developing metabolic disorders requires further study.

Olanzapine treatment was associated with a better quality of life (QoL) in terms of physical health, mood, work, functioning in terms of household, contacts with friends and family, ability to function in everyday life, sex life, and the cumulative assessment of physical and mental health than treatment with quetiapine. In contrast, administration of quetiapine was only associated with the better spending of free time aspect of QoL.

It should be emphasized that, regardless of the type of neuroleptic, the QoL improved with time of their use, in terms of physical health, mood, performance in terms of household tasks, contacts with family, free time activities, and ability to function in everyday life. However, QoL related to work and contacts with friends or sexual life, and the cumulative assessment of physical and mental health, improved in the group treated with olanzapine, only. These results may suggest that treatment with olanzapine is associated with better QoL for patients with 
schizophrenia. These results are consistent with a previous study [17] but opposite to another one, in which treatment with quetiapine significantly improved QoL [18]. It should be noted that the negative effect of neuroleptics on QoL is reflected apparently at the duration of treatment.

Better QoL in terms of physical health, mood, work, household functioning, contacts with friends and family, spending free time, everyday life, sex life, and overall assessment of physical and mental health was observed in those treated with SOT than those treated with ODT. However, it should be noted that regardless of the used form of the drug, improvement of QoL in all aspects during follow-up was observed. This is in contrast to previously published studies that either showed no difference in the impact of the neuroleptic form on QoL [12] or significantly better quality of life during treatment with ODT [19]. These differences may be the effect of higher incidence of adverse effects during treatment with ODT than SOT [13]. However, this aspect has not been evaluated in the study.

A positive attitude to the therapy used in both those treated with olanzapine and with quetiapine increased with time during the follow-up. Treatment with olanzapine more frequently was associated with a positive assessment in terms of perceiving the benefits of treatment, feeling relaxed after treatment, less frequently feeling fatigue and heaviness, more frequent use of the drug, not only in the sense of the disease, more common sense of normalcy during the treatment, rarer unnatural feeling of mind and body control by the drug, frequent sense of mental clarity and frequent use of the drug to prevent the disease. In contrast, treatment with quetiapine less frequently was associated with negative effects on well-being and more frequent use of the drug voluntarily. Thus, it seems that the patients' attitude to the treatment was better among subjects treated with olanzapine than with quetiapine despite a more negative impact on body mass. So far, a more positive attitude of patients to treatment with olanzapine has been demonstrated only in comparison with risperidone and haloperidol [20].

The use of ODT more frequently was associated with a positive patient attitude in terms of perceiving the benefits with treatment and less frequently feeling fatigue and heaviness. We did not observe an effect of the used form of therapy on the perception of well-being. While, treatment with SOT frequently was associated with the voluntary use of the drug, feeling relaxed during treatment, frequent use of drugs not only in the sense of the situation of the disease, a sense of normalcy, rarer unnatural feeling of mind and body control by drugs, frequent feeling of normality, and the use of the drug to prevent the disease. During the follow-up, regardless of the form of neuroleptics used, there was an increase in the percentage of subjects who saw the benefits of treatment, felt relaxed during treatment, had a sense of normality, a feeling of normality and used drugs to prevent the disease and felt decreased negative effects on well-being, felt tired and heaviness and using drugs only sense of the situation of the disease, and experienced unnatural control of the mind and body by drugs. On the other hand, the percentage of subjects voluntarily taking medication increased significantly during the follow-up in the group treated with ODT, only. Thus, similar to the results the atypical neuroleptic form used had no significant effect on the patients' attitude towards the treatment $[12,21]$. It should also be noted that a positive attitude to treatment increased during the follow-up, regardless of the form of atypical neuroleptics used.

The main limitations of the study were the short period of observation and rare serum glucose determination. In addition, the comparison of olanzapine and quetiapine is flawed due to the size of group treated with quetiapine.

\section{Conclusions}

The risk of weight gain is greater during treatment with olanzapine than with quetiapine. Olanzapine use is associated with a better quality of life and more positive attitude of patients towards the treatment. The use of neuroleptics in the ODT form may reduce the risk of weight gain but does not significantly affect the quality of life or patient attitude towards the treatment.

\section{Disclosure}

The study was carried out as a research project supported by a scientific grand of Adamed Sp. z o.o. organized by Europharma M. Rachtan Sp. z o.o. Participaiting general practitioners received payment for completing surveys.

Authors report no conflict of interest.

\section{References}

1. Kaiser S, Heekeren K, Simon JJ. The negative symptoms of schizophrenia: category or continuum? Psychopathology 2011; 44: 345-353.

2. Chen J, Ascher-Syanum H, Nyhuis AW, et al. Reason for continuing or discontinuing olanzepine in the treatment of schizophrenia from the perspective of patients and clinicians. Patient Prefer Adherence 2011; 5: 547-554.

3. Charpentier A, Goudemand M, Thomas P. Therapeutic alliance, a stake in schizophrenia. Encephale 2009; 35: 80-89.

4. Landolt K, Rössler W, Burns T, et al. The interrelation of needs and quality of life in first-episode schizophrenia. Eur Arch Psychiatry Clin Neurosci 2012; 262: 207-216.

5. Rummel-Kluge C, Komossa K, Schwarz S, et al. Head-to-head comparisons of metabolic side-effects of second generation antipsychotics in the treatment of schizophrenia: a systematic review and meta-analysis. Schizophr Res 2010; 123: 225-233. 
6. Leucht S, Corves C, Arbter D, et al. Second-generation versus first-generation antipsychotic drugs for schizophrenia: a meta-analysis. Lancet 2009; 373: 31-41.

7. Simon V, van Winkel R, De Hert M. Are weight gain and metabolic side effects of atypical antipsychotics dose dependent? A literature review. J Clin Psychiatry 2009; 70: 1041-1050.

8. Jayaram MB, Hosalli P, Stroup S. Risperidone versus olanzapine for schizophrenia. Cochrane Database Syst Rev 2006; (2): CD005237.

9. Kommossa K, Rummel-Kluge $\mathrm{C}$, Hunger $\mathrm{H}$, et al. Olanzapine versus other atypical antipsychotics for schizophrenia. Cochrane Database Syst Rev 2010; (3): CD006654.

10. Karagianis J, Hoffmann VP, Arranz B, et al. Orally disintegrating olanzapine and potential differences in treatment-emergent weight gain. Hum Psychopharmacol 2008; 23: 275-281.

11. Arranz B, San L, Dueñas RM, et al. Lower weight gain with the orally disintegrating olanzapine than with standard tablets in first-episode never treated psychotic patients. Hum Psychopharmacol 2007; 22: 11-15.

12. Kusumi I, Honda M, Uemura K, et al. Effect of olanzapine orally disintegrating tablet versus oral standard tablet on body weight in patients with schizophrenia: a randomized open-label trial. Prog Neuropsychopharmacol Biol Psychiatry 2012; 26: 313-317.

13. Czekalla J, Wagner T, Schacht A, et al. Effectiveness and medication acceptance of olanzapine disintegrating tables compared to standard olanzapine tablets in acutely treated psychiatric patients. Patient Prefer Adherence 2007; 1: 19-27.

14. Obesity. Preventing and managing the global epidemic. Report of a WHO, Geneva 1998.

15. Alberti KGMM, Eckel R, Grundy S, et al. Harmonizing the metabolic syndrome. A joint interim statement of the International Diabetes Federation Task Force on Epidemiology and prevention; National Heart, Lung and Blood Institute; American Heart Association; World Heart Federation; International Atherosclerosis Society; and International Association for the Study of Obesity. Circulation 2009; 120: 1640-1645.

16. Biela U, Pająk A, Kaczmarczyk-Chałas K, et al. Incidence of overweight and obesity in women and men between the ages of 20-74. Results of the WOBASZ program. Kardiol Pol 2005; 63 (Suppl 4): S632-S635.

17. Kinon BJ, Noordsy DL, Liu-Seifert H, et al. Randomized, double-blind 6-month comparison of olanzapine and quetiapine in patients with schizophrenia or schizoaffective disorder with prominent negative symptoms and poor functioning. I Clin Psychopharmacol 2006; 26: 453-461.

18. Voruganti LP, Award AG, Parker G, et al. Cognition, functioning and quality of life in schizophrenia treatment: results of a one-year randomized controlled trial of olanzapine and quetiapine. Schizophr Res 2007; 96: 146-155.

19. Ascher-Svanum H, Furiak NM, Lawson AH, et al. Cost-effectiveness of several atypical antipsychotics in orally disintegrating tablets compared with standard oral tablets in the treatment of schizophrenia in the United States. J Med Econ 2012; 15: 531-547.

20. García-Cabeza I, Gómez JC, Sacristán JA, et al. Subjective response to antipsychotic treatment and compliance in schizophrenia. A naturalistic study comparing olanzapine, risperidone and haloperidol (EFESO Study). BMC Psychiatry 2001; 1: 7.

21. Bitter I, Treuer T, Dilbaz N, et al. Patients' preference for olanzapine orodispersible tablet compared with conventional oral tablet in a multinational, randomized, crossover study. Word I Biol Psychiatry 2010; 11: 894-903. 